\title{
The Senior High English Teaching Design Based on the Multiliteracies Pedagogy-From the Perspective of Cultivating Students' Key Competency in English
}

\author{
Xinzhu Liu \\ School of Foreign Languages and Literatures, Chongqing Normal University, Chongqing, China
}

\begin{abstract}
Based on people-oriented moral education, the Key Competency of Chinese Students' Development highlights the importance of cultivating students' key competency, which means that students should have the essential character and core ability to adjust lifelong development and meet the demand of social development. According to the High School English Curriculum Standard (2017 Edition), key competency in English refers to language ability, thinking quality, cultural character and learning ability. And on the basis of multiliteracies pedagogy, linguistic symbols and non-linguistic symbols are combined together to create a multimodal teaching environment. And students will obtain new knowledge through four main stages: situated practice, overt instruction, critical framing and transferred practice, leading students mobilize their multiple senses together when learning English and help improve their comprehensive competence, which is in line with cultivating students' key competency in English. This paper will firstly make a brief introduction of key competency in English based on the High School English Curriculum Standard (2017 Edition) and analyze typical views of multiliteracies pedagogy, then take the reading passage, Learning English from Unit5 Languages around the World, compulsory I, PEP as an example, applying multiliteracies pedagogy to English class, in order to cultivate students' key competency in English to some extent through multiliteracy training.
\end{abstract}

Index Terms - key competency, multiliteracies pedagogy, senior high English teaching

\section{INTRODUCTION}

In China, cultivating students' key competency has been attracting widespread attention among the education area in recent years. In order to strengthen people-oriented moral education and cultivate students' comprehensive English ability, the definition of English disciplinary key competency has been put forward from the High School English Curriculum Standard (2017 Edition) as a guidance for English teachers in senior high. Disciplinary key competency means a concentrated embodiment of disciplinary educational value, and refers to students' correct values, core abilities and essential characters formed gradually through disciplinary studying. It varies from subject to subject and the disciplinary key competency in English includes four main components: language ability, thinking quality, cultural character and learning ability (MOE, 2018). On the basis of the High School English Curriculum Standard(2017 Edition), the educational value of the subject is focused and it is emphasized that the core task of English class should center on how to instruct students to do things through the usage of English and express their ideas in English properly, so as to improve their pragmatic competence. And in the era of globalization and informatization, our living environment is changing rapidly, which can be reflected in the diversification of language and culture and the ways we communicate. People can communicate with others not only by speaking or writing, but also through various channels, such as sounds, images, space and so on. Based on these changes, in 1994, the New London Group put forward an idea of multiliteracy, and the multiliteracies pedagogy they proposed aims at guiding students learn to fetch information from different kind of modals and how to construct meaning and make communication through multimodality. According to multiliteracies pedagogy, the four main aspects of teaching are: situated practice, overt instruction, critical framing and transformed practice (Kalantzis, 2005), which can help promote cultivating students' key competency at a practical level. Hence, Guided by the High School English Curriculum Standard(2017 Edition), this paper takes a teaching design of one reading discourse, which is chosen from Unit 5 Languages around the world, compulsory I, PEP, as an example, integrating multiliteracies pedagogy into teaching design, aiming at cultivating students' key competency in English.

\section{Key COMPETENCY IN ENGLISH}

Cheng Xiaotang (2016) believes that in China, students' key competency can be formed through basic courses teaching, so as to achieve the value of education. According to the High School English Curriculum Standard (2017 Edition), key competency in English refers to language ability, thinking quality, cultural character and learning ability. 
Liu Sen (2018) argues that among these four core competences, language ability is the basic component, while cultural character is considered as the value orientation and thinking ability refers to mental characteristic and learning ability means developing condition. The four elements are closely related to each other and form the key competency in English (Fig. 1).

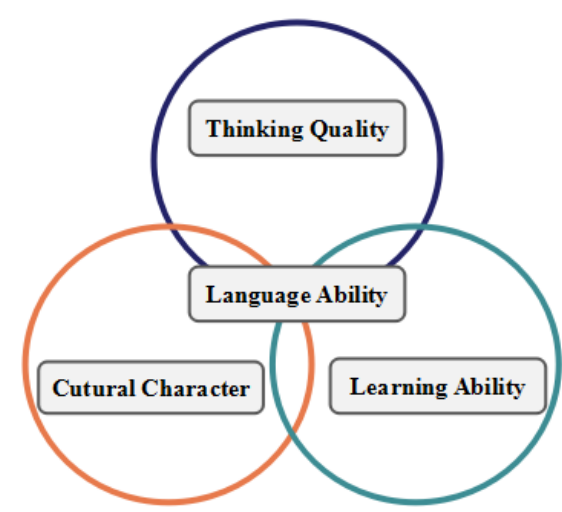

Figure 1. Key competency in English (MOE, 2018)

Language ability: Language ability refers to the ability of using language to understand and express ideas by listening, speaking, reading, writing and observing. The former four components are very classical language skills and have been put forward for years, while the last one, observing, was firstly initiated in 2017, namely the ability to tackle various information from analyzing multimodal discourse, such as ads and tables. Students should combine these language skills and knowledge, transferring information and communicating with others effectively though the context and discourse etc.

Thinking quality: Thinking quality was initially put forward as an individual dimension of the key competency system in English, which refers to the mental characteristic in English studying. It means students' ability of distinguishing, categorizing, summarizing, explaining and analyzing, and also proves their logicality, criticalness and creativity level. This dimension is the one which is most closely related to students' personal development.

Cultural character: Cultural character means the understanding of Chinese and foreign cultures and the cognition of excellent culture, which refers to students' character of knowledge, idea, attitude and behavior students in the era of globalization. It is emphasized from the key competency in English that students' cultural awareness should be cultivated from the perspective of multi-culture. And guided by the core values of socialism, students are able to spread excellent traditional culture, understanding and applying foreign culture and communicating cross culture.

Learning ability: Learning ability is proposed to describe students' capability to use appropriate strategies to study and expand learning channels actively so as to improve their own learning efficiency. It requires students to take measures to keep interest in studying English, setting clear learning goals, knowing how to acquire studying resources, and can choose proper strategies to study, which includes monitoring strategy, reflection strategy, evaluation strategy and adjustment strategy.

\section{TheORETICAl FramewORK: MUltiliteracies PedAgOgy}

According to traditional views, literacy ability mainly stresses reading and writing by applying official language standard. It is always considered as a set of essential skills of coding or decoding written materials. In 1994, multiliteracy was firstly put forward by the New London Group, who made series of assumptions about the method of teaching reading and writing in school to help students be enabled to adapt to the changing society and meet the challenges of economic globalization, cultural pluralism and rapid technological development. The definition of Multiliteracy varies from person to person in academic circles. Williamson (2005) believes that it refers to an ability of reading different kinds of information provided by media and modality. Gentle, Knight\& Corrigan (2006) hold the view that this kind of capability is composed of five parts: linguistic, visual, audio, gestural and spatial. And Hu (2007) concludes that multiliteracy includes 8 layers. Compared with literacy, multiliteracy emphasizes more on the competence to construct multi-meanings and utilize multimodality. In literacy teaching class, teachers pay much attention on reading and writing only but ignore other modalities, and instilled education is the most common method for teaching which restricts students learning range and they are not the subject of the class. In multiliteracy teaching class, various modalities are focused on so that students can use different kinds of channels to achieve effective communication. Aiming at designing constructive concepts and guided by social semiotics, Multiliteracies Pedagogy was put forward (New London Group, 1996): Schools should overcome the shortcomings brought by traditional indoctrinating teaching methods which is language-centered, and transform teaching materials and teaching objectives, laying emphasis on creating multimodal language learning environment to cultivate students' multiliteracy. According to the New London Group, Multiliteracies Pedagogy can be divided into four main teaching aspects: situated practice, overt instruction, critical framing and transformed practice (Kalantzis, 2005). 
Situated practice: Emphasizing solving problems through context, this is a stage for students to experience. Language and context are closely related to each other, that is to say, language communication must happen in situations or contexts. As English teaching should take place in the real context, the teacher can design learning tasks based on real communicative demands or create simulate communicative situations, leading students apply what they learn flexibly and deepen their understanding through practical application. In this stage, the previous and existing learning experience of learners, their linguistic backgrounds and interests, and emotional and cultural needs that will have effects on their learning process should all be taken into consideration.

Overt instruction: On the strength of metalanguage system, in this stage, the teacher provides learning guidance for students to help them gain explicit practical information and understand and know how to use metalanguage. The guidance can lead students transfer what they have learned into newer one, and construct meaning actively and creatively. And based on students' cognitive characteristics and comprehensive development level, when organizing practical teaching activities, teachers should give them specific instruction.

Critical framing: As a stage mainly about teaching analysis, Critical framing emphasizes that when designing meaning, learners should explain its sociocultural context. Students should think critically about what they are learning from different perspectives, and can combine what they have learned independently. In this stage, the teacher should design open questions to train students' critical and creative thinking skills, so as to get an in-depth understanding of new knowledge. Students can know more about values and ideology of multimodal discourses guided by teacher's overt instruction through situated practice. The stage aims at cultivating students' analyzing ability so that they can make rational and impersonal analyses on discourses with various sociocultural backgrounds.

Transformed practice: In this stage, which aims at applications, students are supposed to design meaning in new sociocultural situations, which requires their capabilities of interpreting and constructing multimodal discourses. The premise of Transformed practice is that students can obtain the knowledge of metalanguage constructing the discourse and gain the ability to analyze. On account of the interdependence of language and context, students should understand the demands of the new context and communicative objectives, and also construct meaning to achieve the objectives in the new context. So that they will reinforce what they have already learned, and their ability of applying theoretical knowledge to practical knowledge will also be improved.

\section{An Example of Teaching Design Based on Multiliteracies Pedagogy}

Based on the four parts above, the theory of learning by design was put forward (Kalantzis, 2005), which means that in the classroom, students are supposed to design their learning process actively, choosing proper modals to construct meanings, while teacher only provides learning conditions and demands. According to the theory, Cope et al.(2015) divide learning process into four steps: experiencing, conceptualizing, analyzing and applying, and a detailed framework of learning process has been built (Kalantzis, 2005) ( Fig. 2).

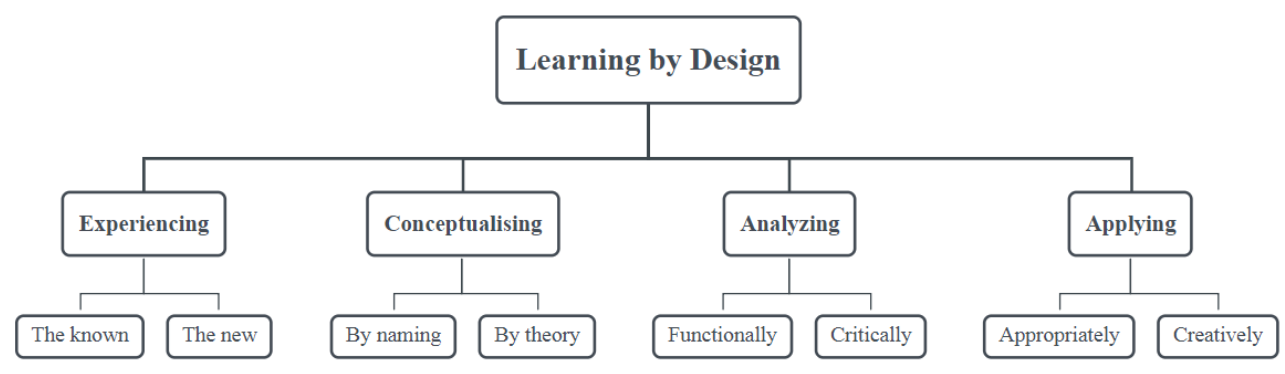

Figure 2. Framework of learning process (Kalantzis, 2005)

In China, cultivating students' key competency generally becomes the main objective in teaching. On the basis of the High School English Curriculum Standard(2017 Edition), English teachers should instruct students to enhance linguistic ability, thinking ability, cultural character and learning ability(MOE, 2018), and help them form good moral character and correct values, which is in line with the views of multiliteracies pedagogy. Hence, aiming at cultivating students' key competency in English, here the author takes Unit 5 Languages around the World, book 1, PEP as an example, making a teaching design of a reading class based on multiliteracies pedagogy.

Analysis of teaching materials: The content of the reading class is taken from Unit 5 Languages around the world from senior English compulsory I, PEP, the title of which is Learning English. As it can be seen from the topic, in this unit, the theme is about various languages around the world. And the literary form of this passage belongs to explosion, talking about problems and advice in learning English, the writing style of which belongs to new media discourse. The passage is composed of three different answers to the question "What are your biggest problems with learning English?". In the passage, Liu Wen, Jia Xin and Li Rui talk about their difficulties which are also seen among senior 
high students in China. And each of them not only talks about their problems, but also gives advice to the former. Words they use are simple and vivid, which is one of the typical characteristics of this kind of informal writing style.

Analysis of students: Students in this class have gained some reading skills after studying near half a year in senior high. They can think independently and some of them have the capability to find information through various channels. As non-English speakers, most of them have learned English for nearly ten years, and meet different kinds of difficulties while learning. So that this topic is closely related to their daily life and can arouse their learning interest easily. However, as teenagers, it is quite hard for them to deal with such problems independently, and they haven't reached maturity of logic and critical thinking. When facing difficulties, sometimes they cannot find proper solutions immediately.

Teaching Objectives:

After the lesson, students will be able to: 1) know how to write a blog; 2) improve skimming and scanning skills; 3) gain useful advice on learning English; 4) form problem-solving awareness.

Teaching Procedures: The teaching procedures are composed of five steps below.

TABLE 1

FRAMEWORK OF TEACHING PROCEDURES

\begin{tabular}{|l|l|}
\hline \multicolumn{1}{|c|}{ TEACHING PROCEDURES } & \multicolumn{1}{c|}{ USAGE OF MULTILITERACIES PEDAGOGY } \\
\hline 1. Lead in & Experiencing \\
\hline 2. Pre-reading & Experiencing; Conceptualizing \\
\hline 3. While-reading & Conceptualizing; Analyzing \\
\hline 4. Post-reading & Analyzing; Applying \\
\hline 5. Homework & Applying \\
\hline
\end{tabular}

\section{Lead in}

The teacher firstly presents some pictures to students and lets them guess which new media does each picture refer to, then shows them a short video about the variety of new media, leading students think about the questions below. And some students are asked to answer the questions.

\section{Q1: What can be called new media?}

Q2: Which kind of new media is commonly used in your daily life, and why?

[Analysis of step1] Based on the view of situated practice, in this step, pictures and videos are applied to arouse students' interests. According to cognitive assimilation theory, questions $1 \& 2$ are arranged as a bridge to help students build a relationship between what they have learned and what they are going to learn. By thinking about the questions, they can easily connect the topic in this lesson with their existing knowledge and experience, which will lay the groundwork for the following study.

\section{Pre-reading}

Students are supposed to search for more information about one kind of new media, blog. And their findings should be based on questions 3,4, 5. Then, on the basis of existing experience, students are supposed to think about questions 6 and 7. In this stage, teacher just acts as a guide to help students interpret and explain the questions properly, and some representatives present their findings to the whole class.

\section{Q3: What is a blog?}

Q4: What are the main features of a blog?

Q5: Are there any differences between blogs in China and blogs in the USA, if so, what are they?

Q6: Which one you think is easier for you, learning Chinese or learning English?

\section{Q7: Why you choose learning Chinese/ learning English?}

[Analysis of step2] In the Pre-reading stage, horizontally, led by questions 3-5, students are firstly supposed to search for information by themselves, which can train their learning ability. Next, questions 6-7 are set from students' real life, and to answer these two questions, they need to think critically and independently based on their own experience, which will help improve their thinking quality. From the vertical perspective, questions $3 \& 4$ are set to give students guidance to construct new meaning by extracting valid information from what they have found, questions 5,6,7 are arranged to lead students make comparisons between two different countries, and their cross-cultural awareness and cultural character can be built up through this process.

\section{While-reading (extensive reading and thinking)}

Activity1: Read the blog, and underline or circle those words, phrases or other modals that can reflect the features of a blog from the passage, for example, informal writing like $\mathrm{Hey,Hi}$, profile photos, likel favorite/comment and login/sign up etc. Are all typical features that can be seen from the given passage (Fig. 3). 


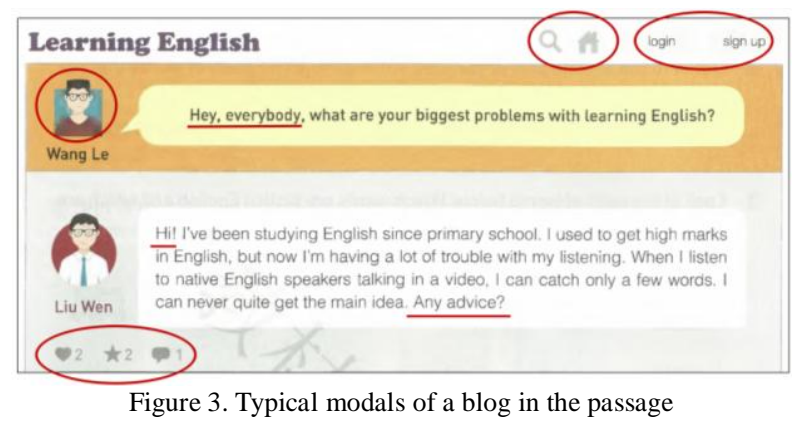

Activity2: Read and answer the following questions:

\section{Q8: Who starts this blog?}

Wang Le.

\section{Q9: Who responds to it?}

Liu Wen, Jia Xin and Li Rui.

\section{Q10: What is the blog mainly about?}

Problems and advice in learning English.

Activity3: Read and fill in the table below, and then discuss: do you think the given advice can really work? can you give them more suggestions?

TABLE 2

TABLE OF ACTIVITY3

\begin{tabular}{|c|c|c|}
\hline \multicolumn{2}{|c|}{ PROBLEM \& ADVICE } \\
\hline PROBLEM & ADVICE \\
\hline Liu Wen & Having a lot of trouble with listening & Listen to English radio programmes \\
\hline Jia Xin & How to be polite in English & $?$ \\
\hline Liu Rui & $?$ & $?$ \\
\hline
\end{tabular}

[Analysis of step3] Firstly, in activity1, on the basis of information found in Pre-reading stage, students are supposed to "change theory into practice". As language and context are closely related to each other, different kinds of modals in the discourse should be considered as a whole and form one context, so that they should be analyzed together. Activities $2 \& 3$ are set to lead students read for specific information of the discourse, aiming at training their reading ability. Besides, activity 3 is also arranged to help students grasp the main structure of blog writing by filling in the form, and those two questions for further discussion are for the sake of promoting their critical thinking skills. And the table in activity 3 will pave the way for the speaking and writing training in Post-reading stage.

\section{Post-reading (intensive reading for writing)}

Activity4: Read the passage, and find out and summarize typical words or phrases from it that can describe something is difficult. For example:

I'm having a lot of trouble with...

My biggest headache is ...

That's really hard!

Etc.

Activity5: Group work: talk about your problems in learning English in your group and ask for advice. Each one in the group should brainstorm some useful suggestions. And words and phrases found in activity4 can be used as many as possible in this activity. Then finish the sheet below, and each group is asked to choose one sheet to make a presentation. Students should apply the structure and modals of blog writing they have learned to prepare for the presentation. Based on the sheet in activity5 and word groups in activity4, students are supposed to write their blogs about problems and advice in learning English. After finishing writing, self-editing and peer-editing should be arranged in this stage.

TABLE 3

TABLE OF ACTIVITY5

\begin{tabular}{|c|c|c|c|}
\hline NAME & PROBLEM & \multicolumn{2}{|c|}{ ADVICE } \\
\hline \multirow{2}{*}{$\mathrm{A}$} & & $\mathrm{B}$ & \\
\cline { 3 - 4 } & & $\mathrm{C}$ & \\
\hline
\end{tabular}

[Analysis of step4] Step4 consists of two activities: in activity4, students are asked to find out typical expressions that can facilitate the group work in activity5, and activity5 is arranged to lead students make appropriate application in the applying stage from the perspective of multiliteracies pedagogy, which can also help promote their cooperative consciousness and logical thinking capability. And by making presentations, they can train their oracy to some extent. 
After this stage, students can also gain some new methods in learning English from other group members' advice. And this stage is a preparation stage for independent writing in step5.

\section{Homework}

Supposing that you have seen a heated discussion on the blog about the biggest problems with how to manage time better, please write a short blog within 120 words, and the following requirements should be included:

1) Your biggest problem with managing time better;

2) How to deal with it;

3) The reason why you give this advice.

[Analysis of step5] As a stage of creative applying, this step is set to train students' independent writing ability and check their learning outcomes of this class. Students are supposed to write a blog within 120 words based on what they have learned from this lesson, and the topic of this writing, how to manage time better, is relevant to their daily life. So that through the writing process after class, they will not only reinforce new knowledge they have studied in this class and transfer it into practice, but also improve their language ability and thinking quality to some extent and form problem-solving awareness.

\section{CONCLUSION}

Guided by multiliteracies pedagogy and aiming at cultivating students' key competency in English, this paper makes a teaching design example of a reading class in China. This example flexibly integrates multiliteracies pedagogy into a reading for writing lesson, arranging five steps: Lead in, Pre-reading, While-reading, Post-reading and Homework. Firstly, Experiencing is blended with Lead in and Pre-reading, aiming at evoking students' existing knowledge and experience. Then, Conceptualizing is integrated into Pre-reading and While-reading so as to instruct students to construct the meaning of blog and summarize its main features. After Functional and Critical Analysis of the discourse in While-reading and Post-reading, Appropriate Application is arranged as a group work in Post-reading, and Creative Application is designed as a writing task in Homework. As the four key competences in English are not separate from each other, in this teaching design, the author mixes the cultivation of them with the whole teaching process, applying multiliteracies pedagogy to train students' language ability and learning ability, and help them form their cultural character and thinking quality through the reading and writing process. Cultivating students' key competency in English is a long-term progress, which plays a significant role in the development of students' comprehensive quality. On the basis of teaching materials and teaching objectives, teachers should improve their teaching methods continuously, and combine multimodal discourses with traditional discourses. So that students will gain the ability to obtain diversified information efficiently in this informationalized world.

\section{REFERENCES}

[1] Cheng Xiaotang. (2017). Key Competences in English and Their Assessment. Journal of China Examinations, 05, 7-14.

[2] Cheng Xiaotang, Zhao Siqi. (2016). On Students' Key Competency in English as a Foreign Language. Curriculum, Teaching Material and Method, 36(05), 79-86.

[3] Chen Yanjun, Liu Dejun. (2016). Theoretical Framework Analysis of Chinese Indigenous English Teaching and Learning Guided by English Disciplinary-based Core Qualities. Curriculum, Teaching Material and Method, 36(03), 50-57.

[4] Cope, B., Kalantzis, M. (2015). The Things You Do to Know: A Introduction to the Pedagogy of Multiliteracies. In Cope, B., Kalantzis, M.(Eds.), A Pedagogy of Multiliteracies: Learning by Design. London: Palgrave, 1-36.

[5] Gentle, F., M. Knight\& M. Corrigan. (2006). Multiliteracies and Information\& Communications Technologies: Ensuring Information Access in the Classroom for Students with Vision Impairment. www.ridbe.org.au (accessed 29/11/2020)

[6] Hu Zhuanglin. (2007). Multimodalization in Social Semiotics. Language Teaching and Linguistic Studies, 01, 9-10.

[7] Kalantzis, M. \& B. Cope. (2005). Learning by Design Guide. Melbourne: Common Ground.

[8] Krashen S D. (2004). Principles and Practice in Second Language Acquisition. California: University of Southern California Press.

[9] Kress. G. (2004). Reading Images: Multimodality, Representation and New Media. Information Design Journal, 12(2), $110-119$.

[10] Li Yanfei, Feng Dezheng. (2019). The Systemic Functional Linguistics Interpretation of the Multiliteracies Pedagogy. Foreign Language Learning Theory and Practice, 02, 8-14.

[11] Liu Sen. (2018). Reflections on Key Competences of EFL Teaching in China Based on the 2018 TESOL Assembly. Teacher Education Research, 30(05), 56-60.

[12] New London Group. (1996). A Pedagogy of Multiliteracies: Designing Social Futures. Harvard Educational Review, 66, 60-93.

[13] Rivers W M. (1997). Interactive Language Teaching. Cambridge: Cambridge University Press.

[14] Sun Qihua. (2017). A Study on the Classroom Teaching Design Based on Cultivation of English Core Accomplishments. Journal of Tianjin Normal University (Elementary Education Edition), 02, 57-61.

[15] The Ministry of Education of the People's Republic of China. (2018). High School English Curriculum Standard(2017 Edition). Beijing: People's Education Press.

[16] Williamson, Ben. (2005). What are Multimodality, Multisemiotics and Multiliteracies?--- A Brief Guide to Some Jargon. http://www.futurelab.org.uk (accessed 29/11/2020) 
[17] Yu Wensen. (2018). On the Significance from Curriculum Theory of Key Competence of Subjects. Educational Research, $39(03), 129-135$.

Xinzhu Liu was born in Mianyang, China in 1997. She is now a postgraduate in the School of Foreign Languages and Literatures, Chongqing Normal University, Chongqing, China. Her research interests include cognitive linguistics and second language acquisition. 